Tema: Metalurgia Secundária

\title{
ANÁLISE COMPARATIVA DE PLACAS REFRATÁRIAS UTILIZADAS NO SISTEMA DE VÁLVULA GAVETA EM PANELA DE AÇO*
}

\section{Resumo}

\author{
Ricardo Thomé da Cruz ${ }^{1}$ \\ Gustavo Frassini. Pelisser \\ Jakson Mattiello ${ }^{2}$ \\ Luciano Ramos Marques \\ Rafael Bruch ${ }^{4}$ \\ Saulo Roca Bragança
}

O material refratário que constitui a placa de válvula gaveta é selecionado de acordo com vários critérios, cuja adequação vai influenciar diretamente no desempenho e vida útil das placas. Estes refratários apresentam alto grau de desenvolvimento tecnológico, demandam tempo para sua substituição em intervalos de poucas corridas e apresentam custo relativamente alto. No presente trabalho foi realizada a caracterização técnica e microestrutural de placas de refratários aluminosos com carbono, de diferentes fornecedores. As propriedades técnicas desses materiais foram relacionadas com o desempenho em serviço. Inclui-se nesse estudo a comparação do refratário novo com o usado (post mortem), relacionando-se os aspectos estruturais com o desgaste do canal da placa. Os resultados mostraram diferenças significativas dos constituintes microestruturais das placas, os quais explicam o melhor desempenho de um material na prática industrial.

Palavras-chaves: Refratários; Válvula gaveta; Desgaste; Aciaria.

\section{COMPARATIVE ANALYSIS OF REFRACTORY PLATE GATE VALVE USED IN STEEL LADLE}

\begin{abstract}
The refractory material constituting the plate gate valve is selected according to various criteria, whose suitability will directly influence the performance and useful life of the plates. These refractories have a high degree of technological development, require time to be replaced every few runs and have relatively high cost. In the present work was carried out technical and microstructural characterization of alumina-carbon refractory plates from different manufacturers. The technical properties of these materials were associated with the service performance. Included in this study the compared performance of the new refractory and the used one (post-mortem), relating the structural aspects with the wearing of the channel plate. The results showed significant differences of microstructural constituents of the plates, which explain the better performance of a material in industrial practice.

Keywords: Refractories; Slide gate; Wear, Steelmaking.

Eng. Materiais, Doutorando, pesquisador, PPGEM, UFRGS, Poá, RS, Brasil.

Eng. Metalúrgico, Mestrando, Eng. Gerdau Riograndense e PPGEM, UFRGS, Poá, RS, Brasil.

Eng. Metalúrgico, M.Sc., Eng. Gerdau Riograndense e PPGEM, UFRGS, Poá, RS, Brasil.

Eng. Materiais, M.Sc., Eng. Gerdau Riograndense e PPGEM, UFRGS, Poá, RS, Brasil

Eng. Químico, Doutor, Professor, PPGEM, DEMAT, UFRGS, Poá, RS, Brasil.
\end{abstract}

* Contribuição técnica ao $45^{\circ}$ Seminário de Aciaria - Internacional, 25 a 28 de maio de 2014, 


\section{INTRODUÇÃO}

Neste trabalho objetivou-se a caracterização das placas refratárias da válvula gaveta utilizadas no controle do fluxo de aço líquido no lingotamento em panela de aço, em aciarias semi-integradas. Inclui-se no estudo a análise de placas novas e postmortem do material refratário, relacionando suas propriedades com o desempenho do mesmo em serviço. As análises foram de caracterização química, física, mecânica e microestrutural.

O desempenho de uma placa refratária de válvula gaveta é medido pelo número de corridas da mesma (ciclo completo da montagem até o vazamento no distribuidor). A vida útil vai depender de alguns critérios, relatados na literatura [1], como acordo com o tipo de aço, comprimento do percurso da placa no mecanismo da válvula gaveta e diâmetro do orifício, entre outros. O tipo de usina e os fatores operacionais (tamanho de panela, temperatura, tempo de lingotamento, abertura livre) vai igualmente influenciar no desempenho do material refratário.

Diferentes tipos de placas refratárias são produzidos principalmente por quatro tipos de materiais: $\mathrm{MgO}-\mathrm{C}, \mathrm{Al}_{2} \mathrm{O}_{3}-\mathrm{C}$, espinélio-C $\left(\mathrm{MgO} \mathrm{Al}_{2} \mathrm{O}_{3}\right)$ e $\mathrm{ZrO}_{2}$. Para aços com cálcio, encontra-se melhor desempenho com as placas de magnésia-carbono $[2,3]$. O material da placa deve fazer frente a uma série de solicitações, como desgaste abrasivo/erosivo, corrosão química, choque térmico, esforços de compressão e tração à frio e à quente. As propriedades das placas vão depender da pureza da composição, da qualidade do processo de fabricação (conformação, ligantes, etc) e da microestrutura. Destaca-se a qualidade dos agregados, do tipo de ligação (carbono, carbono/fase amorfa e cerâmica) e a presença de aditivos.

Os refratários de $\mathrm{Al}_{2} \mathrm{O}_{3}-\mathrm{C}$ são produzidos com agregados de alumina e matriz composta por alumina, grafite, ligante e aditivos antioxidantes, como $\mathrm{Al}$ e $\mathrm{Si}$ metálicos. Estes produzem fases cerâmicas como $\mathrm{AlN} \mathrm{Al}_{4} \mathrm{C}_{3}$, SiC e Sialon que dependendo das condições termodinâmicas e do formato de fases podem aumentar a resistência à quente do material e, simultaneamente, aumentar a resistência ao choque térmico [4]. Aditivos em escala nanométrica vêm sendo investigados e mesmo utilizados, como a alumina em estrutura de folhas ou whiskers, espinélio $\left(\mathrm{MgAl}_{2} \mathrm{O}_{4}\right)$ e nanotubos de carbono, os quais propiciam melhores propriedades físicas e termo-mecânicas [5].

No presente artigo, foram analisados diferentes tipos de placas, inclusive de fornecedores distintos. Todos os produtos são de composição alumina-carbono, mas que variam em algumas propriedades de acordo com os critérios escolhidos pelos fabricantes. Procurou-se explicá-los a partir da caracterização química, física e microestrutural, comparando-se com o desempenho dos mesmos em serviço. Finalizou-se com a análise comparativa entre placa nova e usada (post-mortem), procurando-se explicar os principais fatores de desgaste.

\section{MATERIAIS E MÉTODOS}

Diferentes placas refratárias foram analisadas no presente trabalho. Primeiramente, foram avaliadas duas placas refratárias de um mesmo fornecedor, denominadas B1 e B2, as quais apresentaram diferente desempenho em uso. Depois, analisaram-se comparativamente duas placas de dois fornecedores.

A avaliação da composição química foi realizada por fluorescência de raios-x (Shimadzu espectrômetro, XRF - 1800), e as fases minerais no difratômetro (Phillips modelo X'Pert MPD). A microestrutura foi analisada em Microscópio Eletrônico de

* Contribuição técnica ao $45^{\circ}$ Seminário de Aciaria - Internacional, 25 a 28 de maio de 2014, Porto Alegre, RS, Brasil. 
Varredura - MEV (Hitachi, TM3000). Para esta análise, as amostras foram colocadas sobre um suporte de alumínio previamente preparado com uma fita adesiva de carbono. As amostras foram obtidas por corte a seco e o polimento foi igualmente realizado a seco, com lixas de grana crescente (de 100 a 1200).

\section{RESULTADOS}

\subsection{Análise Comparativa Entre Duas Placas B1 e B2 de um Mesmo Fornecedor}

A placa B1 teve vida útil média superior a 6 corridas, enquanto a placa B2 cerca de 4 corridas. Como as placas são produzidas de modo idêntico, teoricamente, B1 teria que ter uma alumina de melhor qualidade (maior temperatura de sinterização, alumina eletrofundida, alumina de alta pureza) para justificar seu melhor desempenho, em relação à placa B2.

A Tabela 1 apresenta a composição realizada por fluorescência de raios-x. Esta análise mostra pouca diferença na composição das duas placas.

Tabela 1. Composição química elementar por fluorescência de raios-X

\begin{tabular}{|lll|}
\hline $\mathrm{FRX}$ elementar (\%) & $\mathrm{B} 1$ & $\mathrm{~B} 2$ \\
\hline $\mathrm{Al}$ & 47,7 & 51,8 \\
\hline $\mathrm{Si}$ & 31,9 & 29,2 \\
\hline $\mathrm{Zr}$ & 12,6 & 12,3 \\
\hline $\mathrm{Ca}$ & 0,63 & 0,7 \\
\hline $\mathrm{Fe}$ & 1,9 & 0,6 \\
\hline $\mathrm{K}$ & 0,9 & 0,5 \\
\hline Outros & $<0,7$ & $<0,3$ \\
\hline Perda ao fogo & 3,5 & 4,4 \\
\hline
\end{tabular}

$\mathrm{Na}$ análise realizado no MEV (Figuras 1 e 2, Tabelas 2 e 3) pode-se notar a que a alumina é de alta qualidade em ambas as placas, a qual constitui a base da matériaprima que forma esses refratários. No entanto, os materiais possuem igualmente aluminas diferentes em relação ao grau de impurezas. Na comparação de ambas as placas neste quesito, fica claro a maior pureza do material nos agregados da placa B1, com maiores teores de alumina e menores teores de sílica e de alcalinos.

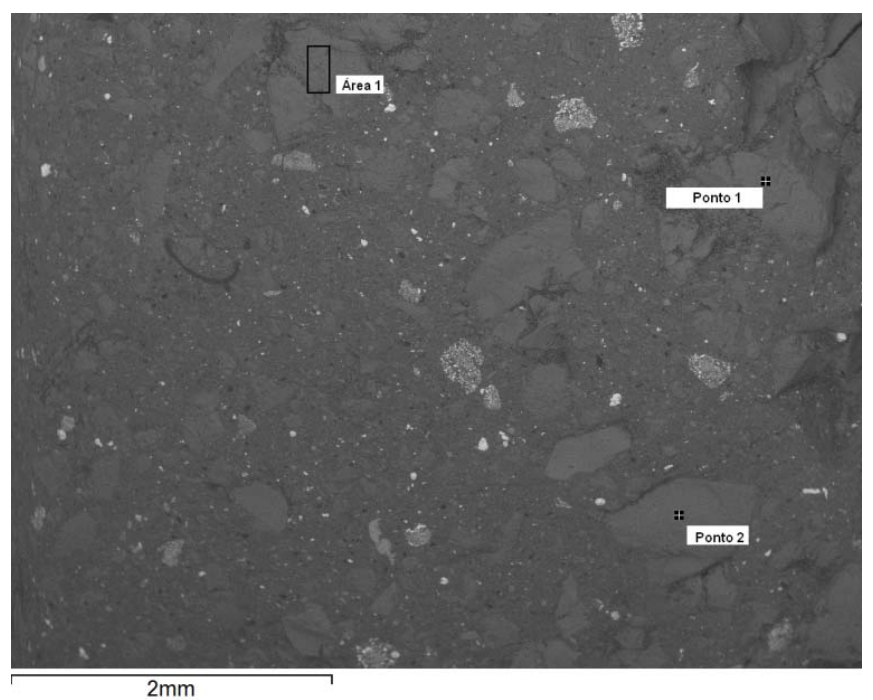

Figura 1. MEV da B1. Pontos EDX relacionados à Tabela 2.

* Contribuição técnica ao 450 Seminário de Aciaria - Internacional, 25 a 28 de maio de 2014, Porto Alegre, RS, Brasil. 
Tabela 2. Composição química via microssonda EDX da Magnesita B1, conforme Figura 1

\begin{tabular}{|cccc|}
\hline Elemento & Área 1 (\%) & Ponto 1 & Ponto 2 \\
\hline Oxigênio & 48,0 & 52,8 & 52,6 \\
Carbono & 20,5 & 15,6 & 8,1 \\
Alumínio & 30,3 & 29,9 & 38,4 \\
Silício & 1,1 & 1,6 & 0,9 \\
\hline
\end{tabular}

Tabela 3. Composição química via microssonda EDX da B2, conforme Figura 2

\begin{tabular}{cccc}
\hline Elemento & Área 1 (\%) & Ponto 1 & Ponto 2 \\
\hline Oxigênio & 36,8 & 39,8 & 45,1 \\
Carbono & 31,8 & 31,0 & 20,9 \\
Alumínio & 21,5 & 20,8 & 23,2 \\
Silício & 9,5 & 7,7 & 10,1 \\
Sódio & 0,4 & 0,3 & 0,6 \\
Zircônio & & 0,3 & \\
Potássio & & & 0,1 \\
\hline
\end{tabular}

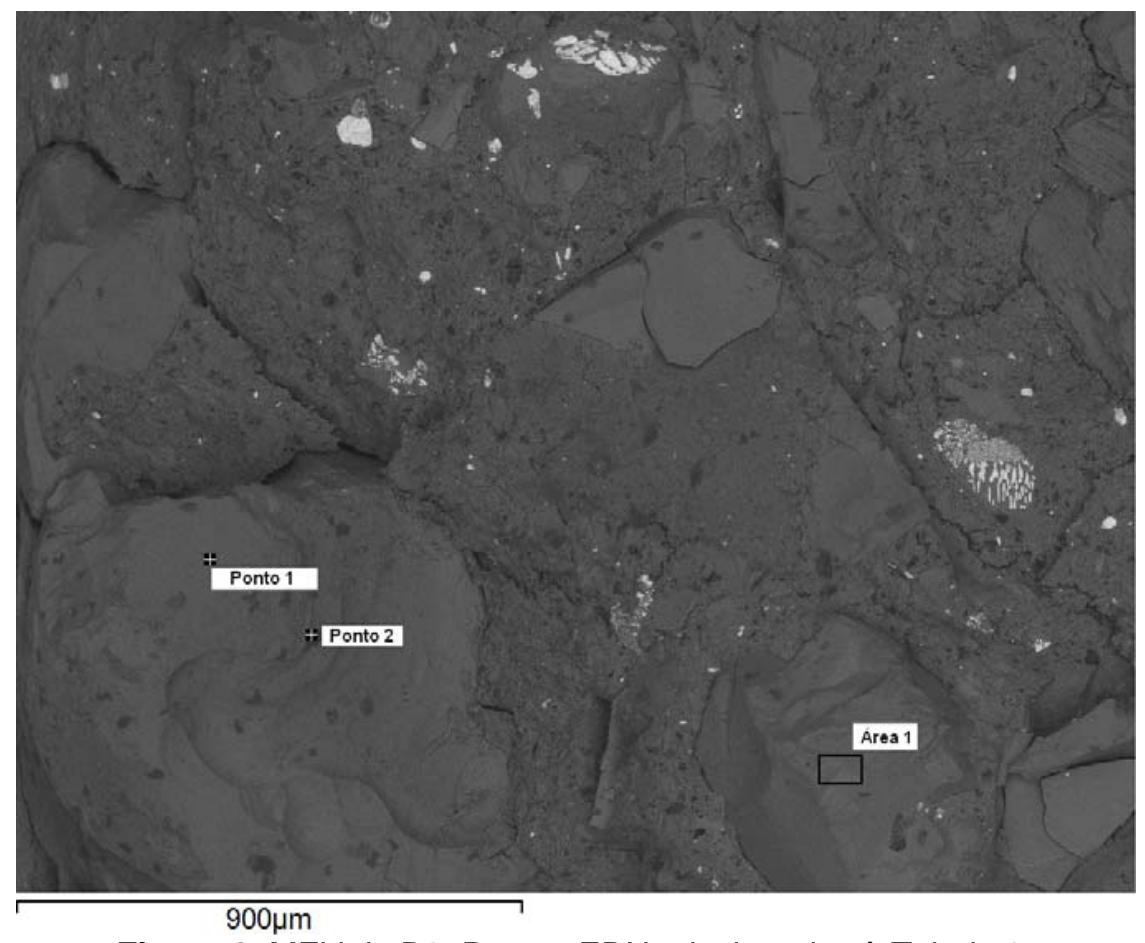

Figura 2. MEV da B2. Pontos EDX relacionados à Tabela 3.

\subsection{Análise das Placas dos Fabricantes A e B}

A Tabela 4 apresenta a composição química e dados de caracterização fornecidos pelo fornecedor. A análise elementar foi realizada por fluorescência de raios- $X$. $A$ placa $A$ contém como diferencial a presença de ligação tipo carbono-silício sendo duas vezes impregnada com piche e coqueificada. A placa B de composição do sistema alumina-zircônia-carbono é também impregnada com piche e coqueificada.

* Contribuição técnica ao $45^{\circ}$ Seminário de Aciaria - Internacional, 25 a 28 de maio de 2014, 

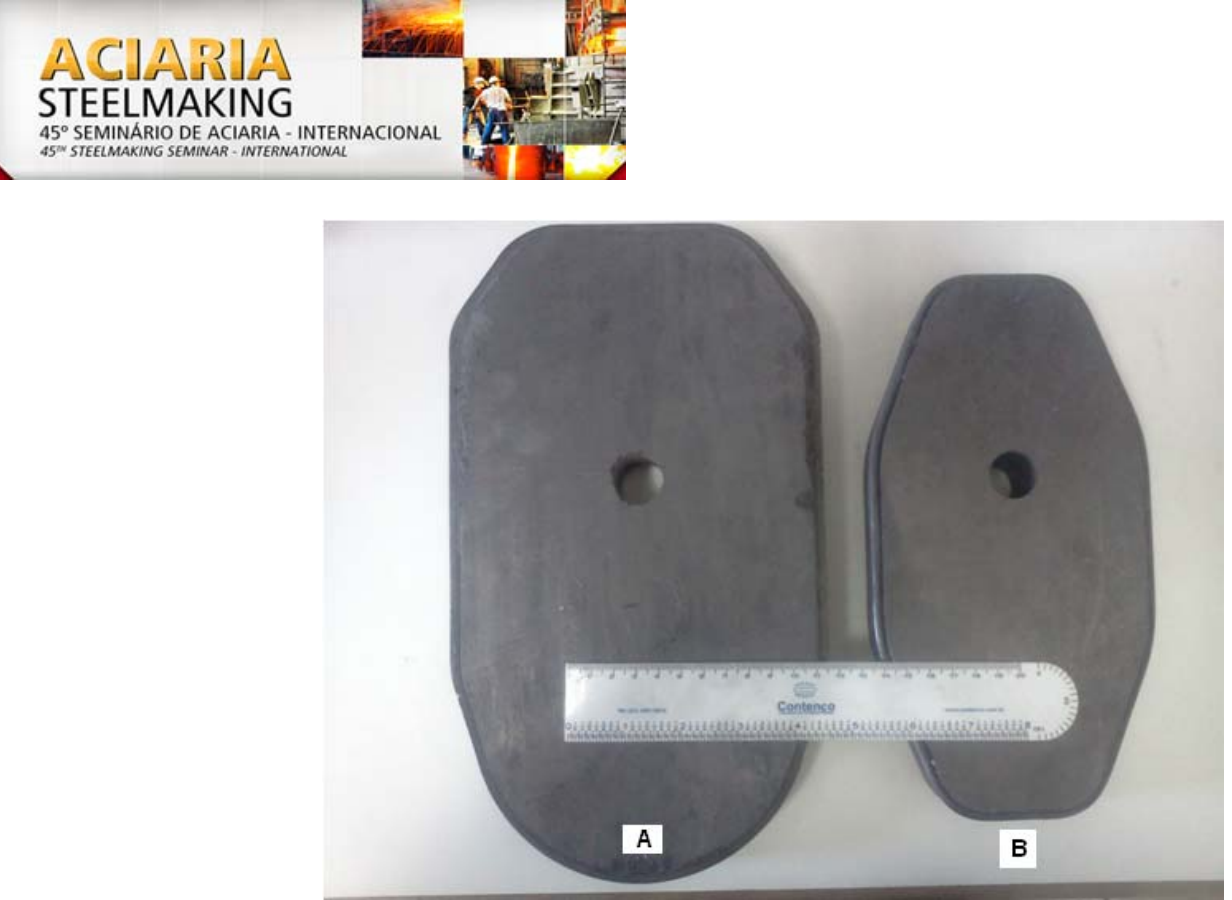

Figura 3. Placas dos fornecedores A e B.

A Figura 3 mostra as duas placas refratárias provenientes de diferentes empresas. Nota-se que elas apresentam um design bastante diferenciado. O refratário $A$, por ser de tamanho superior, teoricamente, apresentaria ganhos em termos de maior percurso de deslizamento entre placas, impactando no controle do fluxo de aço, o que levaria a diminuição de tensões termo-mecânicas e melhor distribuição térmica, sendo que o aquecimento do jato de aço poderia atingir uma maior região da placa. Esta característica pode ser importante principalmente quando se trabalha com o bloqueio parcial do fluxo. Já a peça do fornecedor $B$, possui um design mais enxuto, cumprindo a mesma função, com menor quantidade de material. A Figura 4 apresenta o resultado da análise de DRX comparativa entre as placas $A$ e $B$, após uso, mas retiradas de uma região afastada do orifício do canal.

Tabela 4. Composição química e características das placas A e B, dados dos fornecedores. Análise elementar por fluorescência de raios- $x$

\begin{tabular}{|c|c|c|c|c|c|}
\hline Válvula Gaveta & A & B & Elementar (\%) & A & B \\
\hline $\mathrm{Al}_{2} \mathrm{O}_{3}(\%)$ & 93,1 & $84-88$ & $\mathrm{Al}$ & 51,5 & 51,8 \\
\hline C (\%) & 7,7 & $6-9$ & $\mathrm{Si}$ & 24,7 & 29,2 \\
\hline $\mathrm{SiO}_{2}(\%)$ & 6 & - & $\mathrm{Zr}$ & 14,4 & 12,3 \\
\hline $\mathrm{ZrO}_{2}(\%)$ & - & $1,5-3,5$ & $\mathrm{Ca}$ & 0,5 & 0,7 \\
\hline Densidade aparente $\left(\mathrm{g} / \mathrm{cm}^{3}\right)$ & 3,07 & $3,22-3,34$ & $\mathrm{Fe}$ & 0,5 & 0,6 \\
\hline Porosidade aparente (\%) & 5 & $2-8$ & $\mathrm{~K}$ & 0,6 & 0,5 \\
\hline $\begin{array}{l}\text { Resistência à compressão } \\
\text { (MPa) }\end{array}$ & - & $150-330$ & Outros & $<0,5$ & $<0,3$ \\
\hline Resistência à flexão (MPa) & 32,0 & - & Perda ao fogo & 7,2 & 4,4 \\
\hline $\begin{array}{l}\text { Resistência à flexão à quente, } \\
1400^{\circ} \mathrm{C} \text { x } 30 \text { min. (MPa) }\end{array}$ & & Mín. 14 & & & \\
\hline
\end{tabular}

A placa A apresenta principalmente coríndon e carbono, sendo que estas duas fases estão em comum com a placa B. Em princípio, essas fases estão em maiores concentrações na placa $A$ - isto fica evidenciado pela maior intensidade dos respectivos picos no difratograma $A$ (Figura 4). Além da alumina e do carbono, a

* Contribuição técnica ao $45^{\circ}$ Seminário de Aciaria - Internacional, 25 a 28 de maio de 2014, Porto Alegre, RS, Brasil. 
placa A apresenta também a sílica ( $\mathrm{Si}$, como denominado na Figura 4) em sua composição. Observa-se no difratograma da placa $B$ a presença das fases principais carbono e coríndon $\left(\mathrm{Al}_{2} \mathrm{O}_{3}\right)$, mas também a presença de badeleíta $\left(\mathrm{ZrO}_{2}\right)$. As análises de DRX corroboram com a composição química da folha de dados das duas válvulas. A região analisada, afastada do furo do canal, não apresenta alterações significativas de composição com o uso.

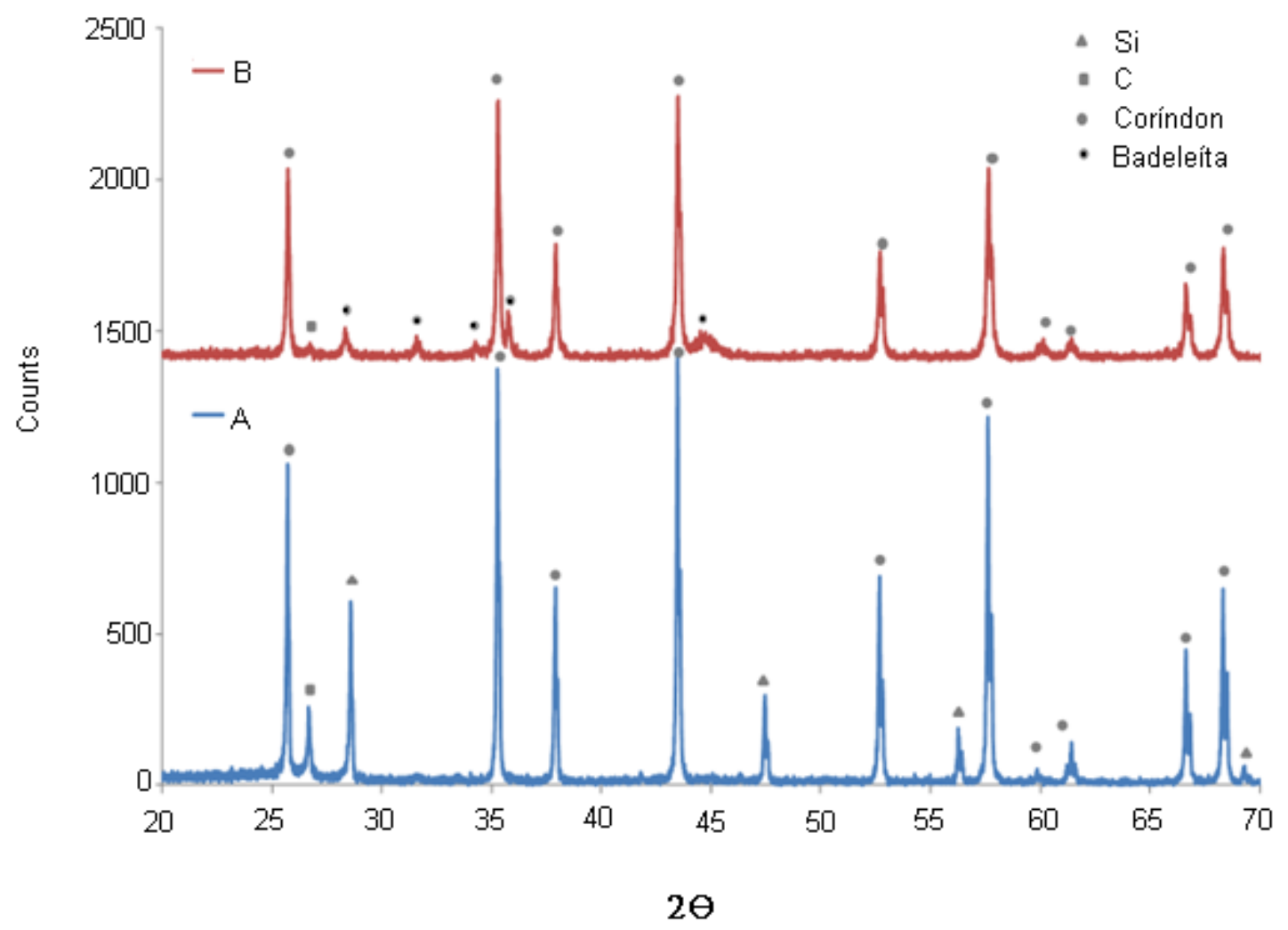

Figura 4. Difratograma comparativo das válvulas gaveta A e B após uso.

A prática industrial revelou que a peça do fornecedor $A$ apresentou uma vida útil média de 6 corridas, enquanto a do fornecedor $B$ teve duração média de 4 corridas. Baseando-se no melhor desempenho da Placa A, inferindo-se apenas a partir das diferenças na composição das placas, poder-se-ia creditar o melhor desempenho da placa $\mathrm{A}$ à presença de sílica. Esse aditivo contribui ao fechamento da porosidade, o que aumenta a resistência à oxidação, mantém o carbono na microestrutura, garantindo, assim, uma maior difusão térmica, menor molhagem e, consequentemente, maior resistência à corrosão. Além disso, a formação de uma fase com a sílica, como silicatos de menor temperatura de fusão, propicia uma maior resistência ao choque térmico, embora possa diminuir a resistência à quente da peça [4]. Os teores de $\mathrm{ZrO}_{2}$ na Placa $\mathrm{B}$ mostram que o fabricante optou por um refinamento da microestrutura, por meio de uma fase que gera um aumento da tenacidade à fratura, por meio do mecanismo de microtrincamento, em decorrência da transformação polimórfica da zircônia [6]. Ressalva-se apenas, que além dessas considerações há uma diferença significativa de design entre as peças.

Observando-se as imagens ao MEV (Figuras 5, 6 e 7), nota-se uma clara diferença entre as microestruturas das placas $A$ e $B$. O melhor desempenho da placa $A$ seria uma consequência da adição de alumina tabular.

* Contribuição técnica ao 45 Seminário de Aciaria - Internacional, 25 a 28 de maio de 2014, Porto Alegre, RS, Brasil. 

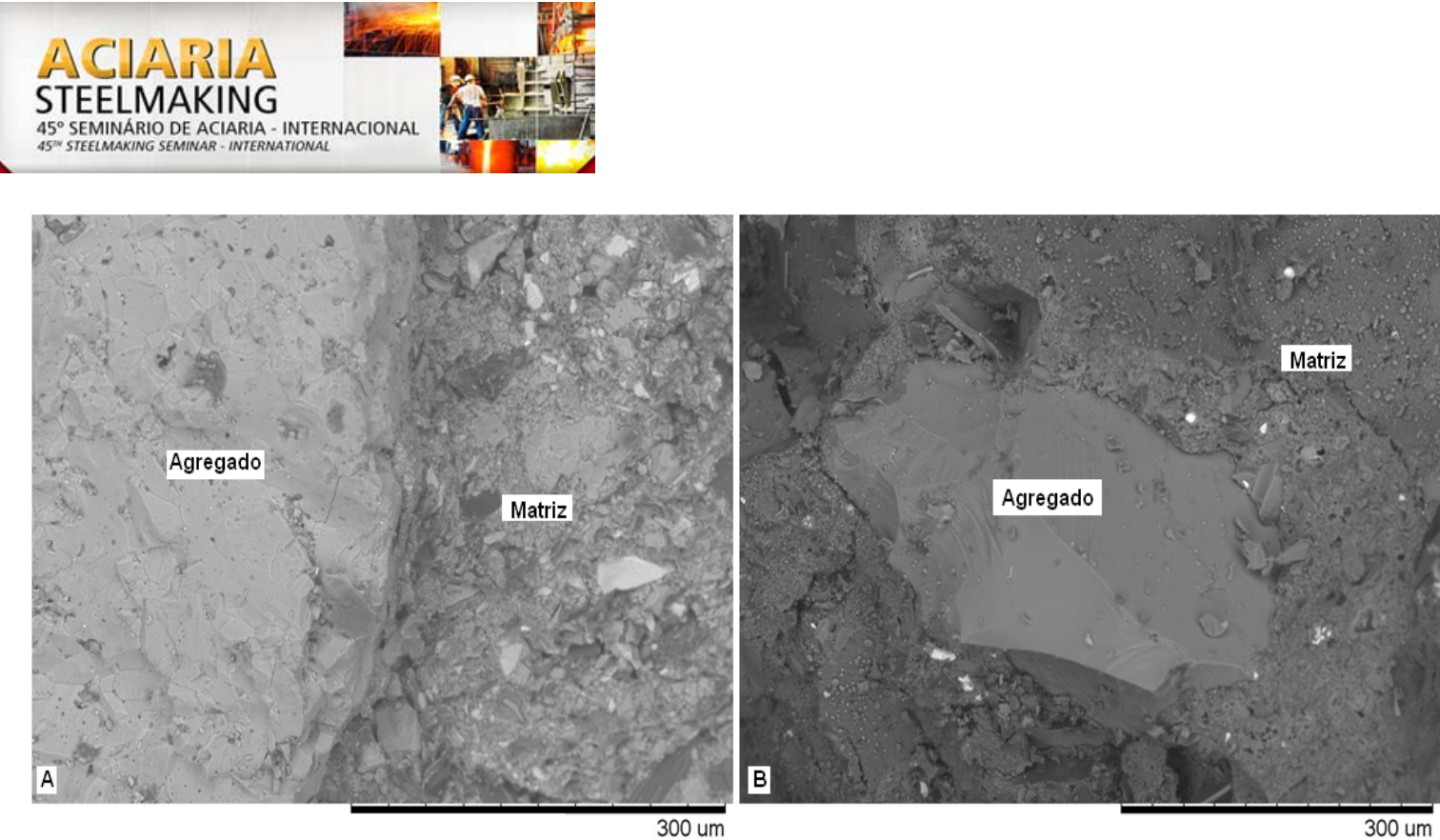

Figura 5. MEV das placas A e B. O agregado em destaque em A é tipicamente alumina tabular.

As análises químicas, via microssonda de energia dispersa, mostram uma pureza consideravelmente maior nos agregados que constituem a placa $\mathrm{A}$ (ponto 1 e área 6, Figura 6), apresentando teores bem menores de sílica que em B (pontos 3 e 4, área 8, na Figura 7). A matriz de A mostra maiores valores de sílica (área 7, Figura 6) cuja adição é intencional (Tabela 4).

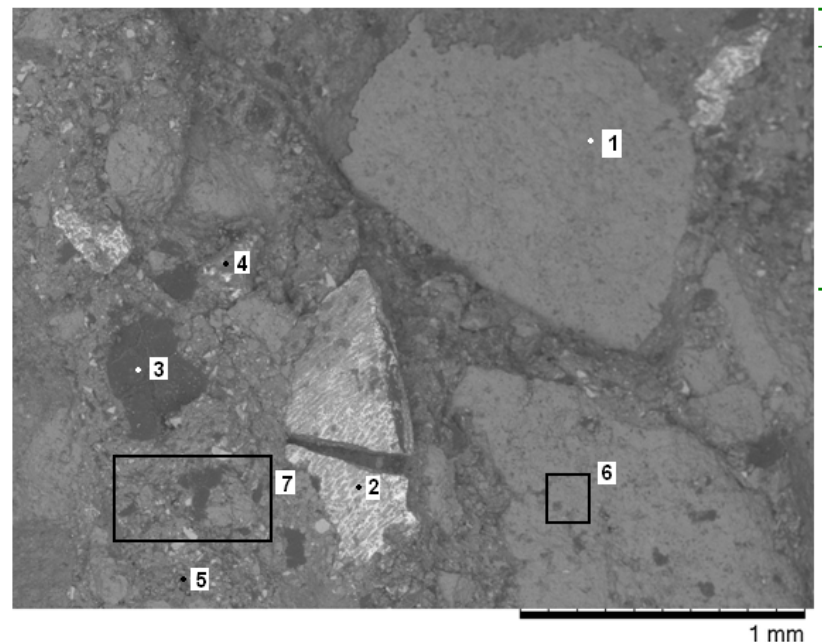

\begin{tabular}{lccccccc}
\hline Elemento / (\%) & 1 & 2 & 3 & 4 & 5 & 6 & 7 \\
\hline Oxigênio & 38,35 & 54,32 & 15,01 & 35,68 & 31,60 & 40,47 & 31,66 \\
Alumínio & 22,17 & 31,40 & 9,27 & 10,89 & 7,58 & 22,34 & 12,36 \\
Carbono & 37,88 & 9,71 & 70,76 & 43,49 & 56,69 & 35,32 & 50,51 \\
Zircônio & & 3,22 & & 1,04 & & & \\
Silício & 1,59 & 0,84 & 4,60 & 6,89 & 3,35 & 1,88 & 5,19 \\
Sódio & & 0,50 & 0,35 & 1,73 & 0,77 & & 0,28 \\
Cálcio & & & & 0,35 & & & \\
\hline
\end{tabular}

Figura 6. Placa A. Análise em MEV/EDS.

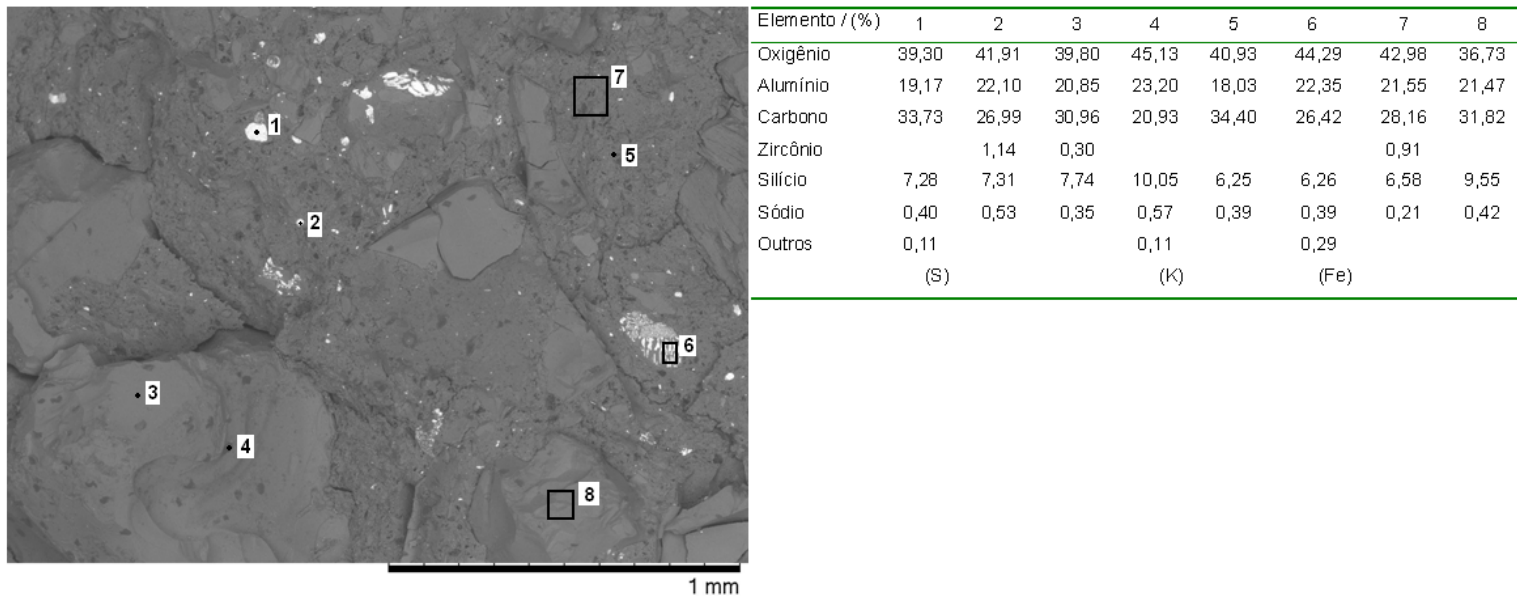

Figura 7. Placa B. Análise em MEV/EDS.

* Contribuição técnica ao $45^{\circ}$ Seminário de Aciaria - Internacional, 25 a 28 de maio de 2014, Porto Alegre, RS, Brasil. 


\subsection{Caracterização da Placa B2 Nova e Usada}

A avaliação da formação de fases de corrosão foi realizada por meio da análise em difração de raios-x. A Figura 8 mostra de maneira esquemática a região da superfície interna do canal incluindo a superfície e uma distância radial de $\sim 2 \mathrm{~mm}$, da qual se retirou as amostras. Outra amostra da região mais externa (afastada do canal) foi igualmente retirada para análise comparativa.

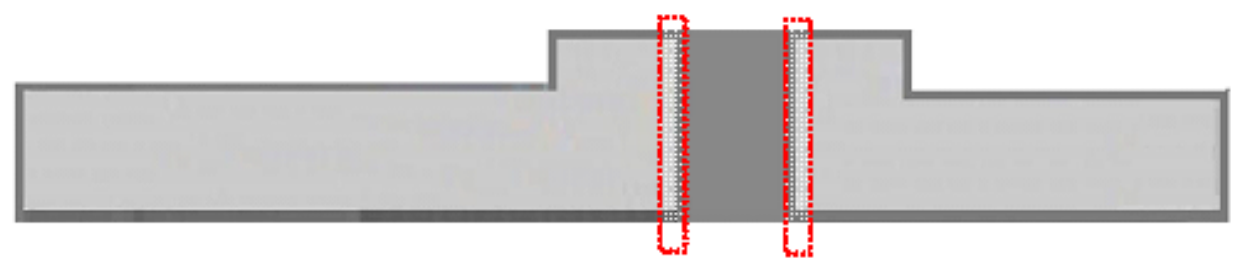

Figura 8. Desenho esquemático da válvula mostrando a região da análise de DRX.

A análise de DRX da região mais interna (superfície $+2 \mathrm{~mm}$ ) da placa nova foi semelhante à análise da região mais externa (superfície $+10 \mathrm{~mm}$ ), não havendo diferenças no material do canal em relação ao restante da placa. A Figura 9 mostra a comparação entre as placas nova e usada da região mais interna (canal).

$\mathrm{Na}$ análise da placa usada além das fases coríndon, grafite e badeleíta (fase minoritária) é possível observar a presença de magnesioferrita $\left(\mathrm{MgFe}_{2} \mathrm{O}_{4}\right)$. Esta fase indica reação entre o óxido de ferro e $\mathrm{MgO}$, sendo o primeiro advindo possivelmente da oxidação do ferro metálico (após lingotamento) e/ou da escória, e o segundo proveniente da escória. É interessante destacar a ausência de compostos característicos da corrosão entre escória e a placa (na placa usada) como os aluminatos de cálcio, fundentes comumente encontrados na corrosão de refratários aluminosos. Sua formação é prevista no diagrama $\mathrm{CaO}-\mathrm{SiO}_{2}-\mathrm{Al}_{2} \mathrm{O}_{3}$. $\mathrm{A}$ ausência de compostos formados a partir de componentes da estrutura da placa $\left(\mathrm{Al}_{2} \mathrm{O}_{3}\right)$ indica uma reação na face exterior (magnesioferrita), provavelmente sem grandes consequências à estrutura da peça, desde que sua infiltração seja mínima. Isto sugere ser, então, o mecanismo de abrasão como o principal fator de desgaste da placa.

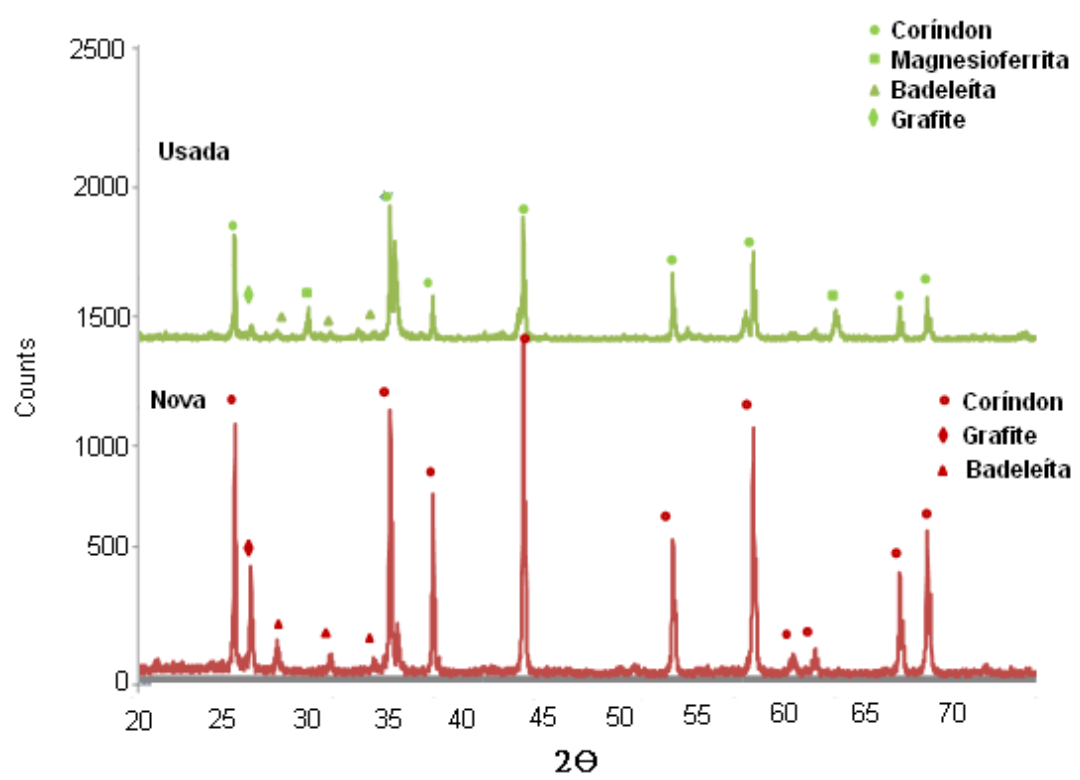

Figura 9. Difratogramas da placa B2 (usada e nova). Amostras retiradas da região do canal da placa (superfície $+\sim 2 \mathrm{~mm}$ ) conforme desenho esquemático Figura 8.

* Contribuição técnica ao $45^{\circ}$ Seminário de Aciaria - Internacional, 25 a 28 de maio de 2014, Porto Alegre, RS, Brasil. 


\section{CONCLUSÃO}

As análises composicionais e microestruturais mostraram as diferenças entre as placas analisadas. As placas de refratários de diferentes fornecedores apresentaram fases distintas $\left(\mathrm{SiO}_{2}\right.$ na placa $\mathrm{A}$, e $\mathrm{ZrO}_{2}$ na placa $\left.\mathrm{B}\right)$. A análise em MEV/EDS mostrou diferenças significativas dos constituintes de ambas, como a presença de alumina tabular e uma menor quantidade de impurezas na Placa $A$.

A análise entre diferentes placas de um mesmo fabricante mostrou a presença de alumina de maior pureza na microestrutura na placa B1, a qual pôde ser associada ao melhor performance da mesma.

Esses fatores explicam o melhor desempenho de uma placa em relação à outra. Baseando-se no desempenho na prática industrial e na análise entre placas novas e usadas (post-mortem), destaca-se que a pureza e qualidade da alumina são os fatores primordiais, uma vez que não foram encontradas fases advindas de reações de corrosão. Por conseguinte, para o presente caso de estudo, o desgaste mecânico é o principal limitador da vida útil das placas.

\section{REFERÊNCIAS}

1 Nascimento ZD. Efeito do cálcio no desgaste das placas refratárias de válvula gaveta de distribuidor no processo de lingotamento contínuo [dissertação de mestrado]. Ouro

Preto: Universidade Federal de Ouro Preto; 2007.

2 Akamine $\mathrm{K}$. MgO-C sliding nozzle plate for casting calcium-alloy-treated steel. Taikabutsu Overseas. 1998;18(1):22-27.

3 Kinoshita $\mathrm{H}$. Development of sliding plate improved on the thermal spalling and corrosion resistence. In: 13 UNITECR Congress; 2003; Japão. Nascimento; 2007 apud.

4 Zhu B, Zhu Y, Lin X, Zhao F. Effect of ceramic bonding phases on the thermomechanical properties of Al2O3-C refractories. Ceramics International. 2013; in press.

5 Roungos V, Aneziris CG. Improved thermal shock performance of Al2O3-C refractories due to nanoscaled additives. Ceramics International. 2012;38:919-927.

6 Schatcht CA. Refractories Handbook. Nova lorque: Marcel Dekker INC.; 2004.

* Contribuição técnica ao $45^{\circ}$ Seminário de Aciaria - Internacional, 25 a 28 de maio de 2014, 